\title{
Mental Health Equity of Filipino Communities in COVID-19: A Framework for Practice and Advocacy
}

\author{
Christian D. Chan, Stacey Diane Arañez Litam
}

The emergence and global spread of COVID-19 precipitated a massive public health crisis combined with multiple incidents of racial discrimination and violence toward Asian American and Pacific Islander (AAPI) communities. Although East Asian communities are more frequently targeted for instances of pandemicrelated racial discrimination, multiple disparities converge upon Filipino communities that affect their access to mental health care in light of COVID-19. This article empowers professional counselors to support the Filipino community by addressing three main areas: (a) describing how COVID-19 contributes to racial microaggressions and institutional racism toward Filipino communities; (b) underscoring how COVID-19 exacerbates exposure to stressors and disparities that influence help-seeking behaviors and utilization of counseling among Filipinos; and (c) outlining how professional counselors can promote racial socialization, outreach, and mental health equity with Filipino communities to mitigate the effects of COVID-19.

Keywords: Asian American, Filipino, mental health equity, COVID-19, discrimination

Asian Americans represent the fastest-growing ethnic group in the United States (Budiman et al., 2019). Following the global outbreak of COVID-19, many Asian Americans and Pacific Islanders (AAPIs) have experienced a substantial increase in race-based hate incidents. These incidents of racial discrimination have included verbal harassment, physical attacks, and discrimination against Asianowned businesses (Jeung \& Nham, 2020), which multiply the harmful effects on psychological wellbeing and life satisfaction among AAPIs (Litam \& Oh, 2020). According to Pew Research Center trends (Ruiz et al., 2020), about three in 10 Asian adults reported they experienced racial discrimination since the outbreak began. Proliferation of anti-Chinese and xenophobic hate speech from political leaders, news outlets, and social media, which touted COVID-19 as the "Chinese virus," further exacerbate instances of race-based discrimination (U.S. Department of Justice, 2020) and echo the Yellow Peril discourse from the late 19th century (Litam, 2020; Poon, 2020).

Although the community is often aggregated, Asian Americans are not a monolithic entity (Choi et al., 2017; Jones-Smith, 2019; Sue et al., 2019). The term Asian American encompasses over 40 distinct subgroups, each with distinct languages, cultures, beliefs, and migration histories (Pew Research Center, 2013; Sue et al., 2019). It is no surprise, therefore, that specific ethnic subgroups would be more affected by the pandemic than others. For example, instances of COVID-19-related racial discrimination disproportionately affect East Asian communities, specifically Chinese migrants and Chinese Americans. An analysis of nearly 1,500 reports of anti-Asian hate incidents indicated approximately $40 \%$ of Chinese individuals reported experiences of discrimination as compared to $16 \%$ of Korean individuals and $5.5 \%$ of Filipinos (Jeung \& Nham, 2020). Although Chinese individuals disproportionately experience overt forms of COVID-19-related discrimination, Filipino migrants and Filipino Americans are not immune to the deleterious effects of the pandemic.

Christian D. Chan, PhD, NCC, is an assistant professor at the University of North Carolina at Greensboro. Stacey Diane Arañez Litam, PhD, NCC, CCMHC, LPCC-S, is an assistant professor at Cleveland State University. Correspondence may be addressed to Christian D. Chan, Department of Counseling and Educational Development, The University of North Carolina at Greensboro, P.0. Box 26170, Greensboro, NC 27402, cdchan@uncg.edu. 
With over 4 million people of Filipino descent residing in the United States (Asian Journal Press, 2018), it is of paramount importance for professional counselors to recognize how the Filipino American experience may compound with additional COVID-19 exposure and related stressors in unique ways that distinctively impact their experiences of stress and mental health. The current article identifies how the racialized climate of COVID-19 influences Filipino-specific microaggressions and the presence of systemic and institutional racism toward Filipino communities. The ways in which COVID-19 exacerbates existing racial disparities across social determinants of health, help-seeking behaviors, and utilization of counseling services are described. Finally, the implications for counseling practice and advocacy are presented in ways that can embolden professional counselors to promote racial socialization, outreach, and health equity with Filipino communities to mitigate the effects of COVID-19.

\section{Health Disparities Among Filipino Americans}

The unprecedented emergence of COVID-19 has affected the global community. As of January 5, 2021, a total of 21,382,296 cases were confirmed and 362,972 deaths had been reported in the United States (Worldometer, n.d.). Although information about how racial and ethnic groups are affected by the pandemic is forthcoming, emerging data suggests that specific groups are disproportionately affected. Professional counselors must be prepared to support communities that may be more vulnerable to pandemic-related stress and face challenges related to medical and mental health care access because of intersecting marginalized identities, such as age, race, ethnicity, gender identity, sexual identity, social class, and migration history (Chan \& Henesy, 2018; Chan et al., 2019; Litam \& Hipolito-Delgado, 2021). For example, the AAPI population may be especially in need of mental health support because of ongoing xenophobic sentiments from political leaders that combine with intergenerational trauma, racial discrimination, and racial trauma (Litam, 2020).

\section{Underutilization of Mental Health Services}

Compared to other Asian American subgroups, Filipinos are the least likely to seek professional mental health services. In a study of 2,230 Filipinos, approximately $73 \%$ had never used any type of mental health service and only $17 \%$ sought help from friends, community members, peers, and religious or spiritual leaders (Gong et al., 2003). Since the Gong et al. (2003) study, a multitude of researchers have documented the persistent disparity of mental health usage and unfavorable attitudes toward professional help-seeking among Filipinos (David \& Nadal, 2013; David et al., 2019; Nadal, 2021; Tuazon et al., 2019), despite high rates of psychological distress (Martinez et al., 2020).

The experiences of Filipino communities uniquely influence aspects of mental health and wellness. Compared to other subgroups of Asian Americans, Filipino Americans with post-traumatic stress experiences tend to exhibit poorer health (Kim et al., 2012; Klest et al., 2013), and report higher rates of racial discrimination $(\mathrm{Li}, 2014)$. As a subgroup, Filipino Americans present to mental health counseling settings with high rates of depression, suicide, HIV, unintended pregnancy, eating disorders, and drug use (David et al., 2017; Klest et al., 2013; Nadal, 2000, 2021). Compared to other Asian subgroups, Filipinos may experience lower social class and employment statuses, which may increase the prevalence of mental health issues (Araneta, 1993). Among Filipinos, intergenerational cultural conflicts and experiences of racial discrimination were identified as significant contributors to depression and suicidal ideation (Choi et al., 2020). The underutilization of professional mental health services and help-seeking among Filipino communities is unusual because of their familiarity with Western notions, systems, and institutions, which surface as traits that are typically associated with mental health help-seeking within the broader AAPI community (Abe-Kim et al., 2002, 2004; Shea \& Yeh, 2008). 


\section{Distinct Experiences of Oppression}

Aspects of Filipino history are characterized by colonization, oppression, and intergenerational racial trauma (David \& Nadal, 2013) and have been rewritten by White voices in ways that communicate how America saved the Philippines from Spanish rule through colonization (Ocampo, 2016). These sentiments remain deeply entrenched within the mindset of many Filipinos in the form of colonial mentality (David \& Nadal, 2013; Tuazon et al., 2019). Colonial mentality refers to the socialized and oppressive mindset characterized by beliefs about the superiority of American values and denigration of Filipino culture and self (David \& Okazaki, 2006a, 2006b). Colonial mentality is the insidious aftermath galvanized through years of intergenerational trauma, U.S. occupation, and socialization under White supremacy (David et al., 2017). Professional counselors must recognize the interplay between colonial mentality and the mental health and well-being of Filipino clients to best support this unique population.

The internalized experiences of oppression perpetuate the denigration of Filipinos by Filipinos as a result of the internalized anti-Black sentiments and notions of White supremacy that remain at the forefront of American history (Ocampo, 2016). The Filipino experience is one that is characterized by forms of discrimination by individuals who reside both within and outside of the Filipino community (Nadal, 2021). For example, Filipinos who espouse a colonial mentality disparage those with Indigenous Filipino traits (i.e., dark skin and textured hair) as unattractive, undesirable, and worthy of shame (Angan, 2013; David, 2020; Mendoza, 2014). Filipinos also experience a sense of otherness within the AAPI community and from other communities of color because their history, culture, and phenotype combine in ways that "break the rules of race" (Ocampo, 2016, p. 13). Although Filipinos are sometimes confused with individuals from Chinese communities, they are not typically perceived as Asian or East Asian (Lee, 2020) and are often mistaken for Black or Latinx (Ocampo, 2016; Sanchez \& Gaw, 2007). These pervasive experiences render the Filipino identity invisible (Nadal, 2021). Ultimately, Filipinos remain among the most mislabeled and culturally marginalized of Asian Americans (Sanchez \& Gaw, 2007). Professional counselors who work with Filipino clients must obtain a deeper understanding of how these unique experiences of invisibility and colonial mentality continue to affect the minds and the worldviews of Filipinos and Filipino Americans.

\section{Risk Factors for COVID-19 Exposure}

The burgeoning rate of COVID-19 cases has devastated hospitals and medical settings. The overwhelming strain faced by medical communities uniquely affects Filipino migrants and Filipino Americans who are overrepresented in health care and disproportionately at risk of COVID-19 exposure (National Nurses United, 2020). The overrepresentation of Filipinos in health care, particularly within the nursing profession, is directly tied to the history of U.S. colonization. Following the U.S. occupation of the Philippines from 1899 to 1946, the Filipino zeitgeist became imbued with profound cultural notions of American superiority and affinity for Westernized attitudes, behaviors, and values (David et al., 2017). For example, the introduction of the American nursing curricula by U.S. Army personnel during the Spanish-American war (McFarling, 2020) instilled pervasive cultural influences that positioned the nursing profession as a viable strategy to escape political and economic instability in pursuit of a better life in the United States (Choy, 2003). These cultural notions have culminated to make the Philippines the leading exporter of nurses in the world (Choy, 2003; Espiritu, 2016). Of the immigrant health care workers across the United States, an estimated $28 \%$ of registered nurses, $4 \%$ of physicians and surgeons, and $12 \%$ of home health aides are Filipinos (Batalova, 2020). About 150,000 registered nurses in the United States are Filipino, equating to about $4 \%$ of the overall nursing population (McFarling, 2020; National Nurses United, 2020). According to the National Nurses United (2020) report, 31.5\% of deaths among registered nurses and $54 \%$ of deaths among registered nurses of color were Filipinos. Based on these statistics, Filipinos face disproportionate exposure to pandemic-related stressors and death that may increase the risk for mental health issues. 
Individuals of Filipino descent may also face significant COVID-19-related challenges, as they are predisposed to several health conditions that have been linked with poorer treatment prognosis and outcomes (Ghimire et al., 2018; Maxwell et al., 2012). Compared to other racial and ethnic subgroups, Filipinos residing in California had higher rates of type II diabetes, asthma, and cardiovascular disease (Adia et al., 2020). High rates of hypertension, cholesterol, and diabetes were also noted in studies of Filipino Americans residing in the greater Philadelphia region (Bhimla et al., 2017) and in Las Vegas, Nevada (Ghimire et al., 2018). One study of Filipinos residing in the New York metropolitan area indicated rates of obesity significantly increased the longer Filipino immigrants resided in the United States (Afable et al., 2016). The Centers for Disease Control and Prevention (2021) associated each of these underlying medical conditions with a greater likelihood for hospitalization, intensive care, use of a ventilator, and increased mortality. Filipino Americans also tend to report lower social class and employment statuses as compared to other Asian Americans, which may contribute to higher rates of mental health issues and create barriers to health care access (Adia et al., 2020; Sue et al., 2019).

\section{Cultural Barriers to Professional Mental Health Services}

Filipinos face culturally rooted barriers to seeking professional mental health services that may include fears related to reputation, endorsement of fatalistic attitudes, religiousness, communication barriers, and lack of culturally competent services (Gong et al., 2003; Nadal, 2021; Pacquiao, 2004). The presence of mental illness stigma is also deeply entrenched within Filipino communities (Appel et al., 2011; Augsberger et al., 2015; Tuazon et al., 2019). In many traditional Filipino families, mental illness is mitigated by addressing personal and emotional problems with family and close friends, and through faith in God (David \& Nadal, 2013). Rejection of mental illness is based on the belief that individuals who receive counseling or therapy are crazy, dangerous, and unpredictable (de Torres, 2002; Nadal, 2021).

\section{Connection and Kinship}

Given the central prominence of family, it is no surprise that Filipino individuals' mental health begins to suffer when their connection to community and kinship is compromised. Although relatively few studies on Filipino mental health exist, Filipinos and Filipino Americans consistently report familyrelated issues as among the most stressful. In one study of Filipino and Korean families in the Midwest $(N=1,574)$, the presence of intergenerational family conflict significantly contributed to an increase in depressive symptoms and suicidal ideation (Choi et al., 2020). In another study of Filipino Americans, quality time with family, friends, and community was identified as an important factor in mitigating the effects of depression (Edman \& Johnson, 1999). The centralized role of Filipino families uniquely combines with a group mentality in ways that may additionally hinder rates of professional help-seeking.

\section{Hiya and Amor Propio}

Notions of hiya and amor propio each represent culturally specific barriers to seeking mental health care. According to Gong and colleagues (2003), hiya and amor propio are related to the East Asian notions of saving face. While hiya emphasizes the more extensive experience of shame that arises from fear of losing face, amor propio is associated with concepts of self-esteem linked to the desire to maintain social acceptance. A loss of amor propio would result in a loss of face and may compromise the cherished position of community acceptance (Gong et al., 2003). Filipino Americans may thus avoid seeking professional mental health services because of combined feelings of shame (hiya) linked to beliefs that one has failed or is unable to overcome their problems independently, and fears of losing social positioning within one's community (amor propio). To experience amor propio would put a Filipinoor worse, their family - at risk for tsismis, or gossip. Indeed, avoiding behaviors that may lead others within the Filipino community to engage in tsismis about the client or their family is a significant factor 
that guides choices and behaviors. Engaging in behaviors that result in one's family becoming the focus of tsismis is considered highly shameful and reprehensible among Filipino communities.

\section{Bahala Na}

The Tagalog term bahala na refers to the sense of optimistic fatalism that characterizes the shared experiences of many Filipinos and Filipino Americans. Bahala na can be evidenced through Filipino cultural expectations to endure emotional problems and avoid discussion of personal issues. This core attitude may have deleterious effects on mental health and help-seeking, as many Filipinos are socialized to deny or minimize stressful experiences or to simply endure emotional problems (Araneta, 1993; Sanchez \& Gaw, 2007). A qualitative analysis of 33 interviews and 18 focus groups of Filipino Americans indicated bahala na may combine with religious beliefs to create additional barriers to addressing mental health problems (Javier et al., 2014). For example, virtuous and religious Filipinos and Filipino Americans may endorse bahala na attitudes by believing their higher power has instilled purposeful challenges that can be overcome by sufficient faith and endurance (Javier et al., 2014).

\section{Hindi Ibang Tao}

Moreover, many Filipinos and Filipino Americans demonstrate hesitance to trust individuals who are considered outsiders. When interactions with those considered other cannot be avoided, traditional Filipinos tend to be reticent, conceal their real emotions, and avoid disclosure of personal thoughts, needs, and beliefs (Pasco et al., 2004). Filipino community members place a large value on in-group versus out-group members and largely prefer to seek support from helping professionals within the Filipino community, rather than from others outside of the group (Gong et al., 2003). Individuals who are hindi ibang tao (in Tagalog, "one of us") are differentiated from those who are ibang tao (in Tagalog, "not one of us"), which influences interactions and amount of trust given to health care providers (Sanchez \& Gaw, 2007). White counselors may be able to bridge the cultural gap with Filipino clients to become hindi ibang tao by exhibiting respect, approachability, and a willingness to consider the specific influences of Filipino history and the importance of family (Sanchez \& Gaw, 2007). Professional counselors who overlook, minimize, or disregard these cultural values risk higher rates of early termination and may experience their Filipino clients as exhibiting little emotion (Nadal, 2021). Filipino clients who are not yet comfortable with professional counselors may interact in a polite, yet superficial manner because culturally responsive relationships and trust have not been developed (Gong et al., 2003; Pasco et al., 2004; Tuazon et al., 2019).

\section{Pakikisama and Kapwa}

Another Filipino cultural barrier is pakikisama, or the notion that when one belongs to a group, one should be wholly dedicated to pleasing the group (Bautista, 1999; Nadal, 2021). Filipino core values extend beyond the general notion of collectivism and include kapwa, an Indigenous worldview in which the self is not distinguished from others (David et al., 2017; Enriquez, 2010). Thus, Filipinos do not solely act in ways that benefit the group; they are also expected to make decisions that please other group members, even at the expense of their own desires, needs, or mental health (Nadal, 2021). The cultural notions of pakikisama and kapwa interplay with amor propio in ways that have detrimental effects on Filipinos in dire need of mental health support. For example, a second-generation Filipino American may recognize that their suicidal thoughts and experiences of depression may be worthy of mental health support, but recognition of cultural mistrust toward those deemed other may risk their family's social acceptance (amor propio). Risking the family's social acceptance could ultimately violate group wishes (pakikisama) and may subject their family to stigma and gossip (tsismis). 


\section{Implications for Practice and Advocacy in Professional Counseling}

The COVID-19 pandemic and increased visibility to discrimination against Asian Americans illuminates the importance of addressing the presence of mental health barriers among Filipino communities. Filipino communities face complex barriers rooted in colonialism, racism, and colorism that negatively affect their overall mental health (David \& Nadal, 2013; Tuazon et al., 2019; Woo et al., 2020). The combination of educational, health, and welfare disparities culminate in poorer health outcomes for Filipino American communities compared to other ethnic Asian groups (Adia et al., 2020). Many of these identifiable barriers and forces of oppression increase the racial trauma narratives incurred among Filipino communities (David et al., 2017; Klest et al., 2013); deny the impact of microaggressions and discrimination (Nadal et al., 2014); divest resources that support economic, educational, and social well-being (Nadal, 2021; Smith \& Weinstock, 2019); and discourage the utilization of needed counseling spaces (Tuazon et al., 2019).

Cultivating cultural sensitivity in health care providers can buffer the psychological toll and emotional consequences of negative health care encounters for historically marginalized communities (Flynn et al., 2020), including Filipinos. Findings associated with health equity and help-seeking behaviors (e.g., Flynn et al., 2020; Ghimire et al., 2018) have significant ramifications for Filipino communities that face a litany of barriers to counseling services (Gong et al., 2003; Tuazon et al., 2019). In light of COVID-19, professional counselors are encouraged to employ culturally responsive interpersonal and systemic interventions that promote the sustainable mental health equity of Filipino communities.

\section{Promoting Racial Socialization and Critical Consciousness}

Reducing barriers for mental health access is connected to protective factors, actions, and cultural capital instilled across generations of Filipino communities (David et al., 2017). Filipino communities draw from several generations of colonization, which continues to affect second-generation Filipinos living in the United States (David \& Okazaki, 2006a, 2006b). Experiences of historical colonization, forced assimilation into other cultures, and the erasure of Filipino cultural values have resulted in a range of Eurocentrically biased and historically oppressive experiences (Choi et al., 2020; David \& Nadal, 2013). These experiences have prepared Filipino communities, intergenerationally and collectively, to respond to experiences of discrimination in ways that preserve their cultural values (David et al., 2017). The preservation of Filipino cultural values across generations has bolstered a type of protective factor through racial socialization, where parents and families teach future generations of children about race and racism (Juang et al., 2017). Ultimately, preparing future generations of Filipinos to respond to racial oppression can protect cultural assets (David et al., 2017). In fact, a study by Woo and colleagues (2020) indicated Filipino parents who prepared their children to respond to racial discrimination prepared them for bias and strengthened their ethnic identity.

One strategy that professional counselors can use to infuse social justice in their work is to help Filipino clients raise their critical consciousness. Critical consciousness is an approach that helps clients to recognize the systemic factors contributing to their barriers with mental health utilization and mental health stressors (David et al., 2019; Diemer et al., 2016; Ratts \& Greenleaf, 2018; Seider et al., 2020) and to feel empowered to take part in action (Ratts et al., 2016; Watts \& Hipolito-Delgado, 2015). Professional counselors can raise Filipino clients' critical consciousness by engaging in conversations about how the history of colonization, endorsement of colonial mentality, and systemic factors continue to marginalize Filipinos (David et al., 2019). Connecting critical consciousness to COVID-19, professional counselors can highlight how public anti-Asian discourse echoes centuries of oppression and leads to cultural mistrust 
of health care providers, particularly professional counselors (Litam, 2020; Ratts \& Greenleaf, 2018; Tuazon et al., 2019). Similarly, professional counselors can raise the critical consciousness of Filipino clients by discussing the effects of race-based trauma and racial violence as a result of COVID-19 (Litam, 2020; Nadal, 2021). Including these topics during counseling can be instrumental for detecting the effects of race-based trauma, such as somatic symptoms, while grasping the manifestation of pandemic stress (Taylor et al., 2020). As health care providers focus predominantly on wellness, professional counselors play a significant part in deconstructing the connections and nuances among race-based traumatic stress and pandemic stress (Ratts \& Greenleaf, 2018).

Additionally, professional counselors can raise the critical consciousness of Filipino clients by examining the intersection of underlying health disparities, Filipino core values, and overrepresentation of Filipinos working in health care positions during COVID-19 through a trauma-informed lens. Aligned with this perspective, professional counselors can identify and discuss how intergenerational trauma narratives may have persisted across generations of Filipino communities (David \& Okazaki, 2006b; David et al., 2019; Nadal, 2021; Tuazon et al., 2019) in ways that have adverse effects on mental health. For example, professional counselors may support Filipino clients to critically reflect on how socialized messages from parents and elders with intergenerational trauma may have contributed to the internalization of colonial mentality. Professional counselors may also broach these cultural factors by promoting discussions within clients' families and communities about the cultural preservation of Filipino identities (Choi et al., 2017, 2020; David et al., 2017).

\section{Culturally Congruent Coping Responses Among Filipino Clients}

Professional counselors can help Filipino clients who seek counseling during COVID-19 by empowering them to engage in coping responses that cultivate their cultural assets and strengthen their ethnic identity (David et al., 2017, 2019; Woo et al., 2020). Before implementing these culturally sensitive strategies, professional counselors must reflect on whether they hold individualistic notions and Western attitudes about which coping responses are deemed helpful or unhelpful to mitigate the effects of racial discrimination (Oh et al., in press; Sue et al., 2019). Following experiences of racial discrimination and stress, Filipinos tend to use disengagement coping responses (Centeno \& Fernandez, 2020; Tuason et al., 2007). Following an assessment of coping responses, professional counselors can support Filipino clients by reinforcing culturally responsive disengagement coping strategies, such as tiyaga (Tagalog for "patience and endurance") and lakas ng loob (Tagalog for "inner strength and hardiness"), to promote resilience and demonstrate flexibility.

Given these central cultural values, professional counselors must be cautioned from solely using emotion-centered counseling strategies that center experiences of stress, racial trauma, or COVID-19related discrimination (Litam, 2020). Instead, Filipino clients may benefit from interventions that draw from their cultural values of endurance (tiyaga) and inner strength (lakas ng loob) to refocus energy toward cultivating meaningful relationships and roles (David \& Nadal, 2013; David et al., 2017). For example, Filipino clients who are concerned about the wellness of their community may experience a heightened sense of purpose and inner strength by reflecting on how their actions have already benefitted their families rather than focusing on their fears. Indeed, when stressful experiences occur, Filipinos have a long history of demonstrating resilience. Empowering Filipino clients to reflect on the historical ways that the Filipino community has evidenced resilience and inner strength may cultivate a strong sense of Filipino pride and strengthen ethnic identity as protective factors to mental health distress (Choi et al., 2020; David et al., 2019; Tuazon et al., 2019). 
Filipinos may also benefit from engagement coping strategies, such as prayer, employing religious and spiritual resources, and responding with humor, to promote health and wellness (Nadal, 2021; Sanchez \& Gaw, 2007). Counselors can help Filipino clients leverage engagement coping strategies by reflecting on existing responses to stress. Counselors may ask, "How have you intentionally responded to stressful events in the past?" and "How did these ways of coping impact your levels of stress?" Counselors can also demonstrate culturally sensitive strategies and lines of questioning that move from general, shared Filipino values to specific client experiences. For example, counselors can state: "Many Filipinos find peace of mind through prayer, religious practices, and humor. I'm wondering if this is true for you?" Because of the community orientation and collectivism embedded within Filipino culture, it may be helpful for counselors to elaborate on cultural contexts and relationships that inform coping strategies: "I am wondering how you may have seen some of these coping strategies in your home, family, or community. How might you have experienced a coping strategy like humor within your own community?" This statement communicates a familiarity with Filipino cultural values and creates an invitation for clients to explore their coping resources.

\section{Creating Outreach Initiatives and Partnerships}

For counselors placed in school and community settings, challenging the systemic effects of COVID-19 among Filipino communities necessitates community partnerships and integrated care settings to achieve health equity (Adia et al., 2019). Health equity initiatives call for two types of overarching efforts to sustain long-term benefits and changes. One aspect of health equity relates to developing community partnerships as a method to intentionally increase health literacy within the community (Guo et al., 2018). Increasing mental health literacy, including education about counseling services and a comprehensive approach to wellness, operates as a direct intervention to cultural and linguistic barriers that precede negative health care experiences (Flynn et al., 2020). Increasing mental health literacy in Filipino communities may also normalize the process of professional mental health services, challenge the cultural notion that those who seek mental health care are crazy, and offer strength-based language related to counseling services (Ghimire et al., 2018; Maxwell et al., 2012; Nadal, 2021). Expanding on recommendations by Tuazon and colleagues (2019), professional counselors can challenge the systemic effects of COVID-19 in Filipino communities by helping community stakeholders understand culturally responsive practices for seeking professional mental health services. Professional counselors employed in community settings can leverage opportunities to liaise with Filipino community organizations and leaders to increase the utilization of counseling services as a preventive method (Graham et al., 2018; Maxwell et al., 2012), especially in response to the increased mental health issues in Filipinos following COVID-19. Professional counselors employed in community settings are therefore uniquely positioned to broach cultural factors of colonialism and systemic racism while addressing the urgency of mental health services for Filipino communities during COVID-19 (Day-Vines et al., 2018, 2020).

\section{Increasing Visibility of Filipino Counselors}

The second aspect of health equity initiatives focuses on increasing representation in the pipeline of providers. Although Flynn and colleagues (2020) documented the importance of culturally responsive practices to buffer negative health care experiences, public health scholars have generally identified that the representation of professional counselors is crucial for encouraging historically marginalized communities to seek services (Campbell, 2019; Graham et al., 2018; Griffith, 2018). According to Campbell (2019), historically marginalized clients are more likely to pursue services and demonstrate an openness to speak with professional counselors who are representative of their communities. In addition to increasing Filipino counselors and counselor educators in the pipeline (Tuazon et al., 2019), professional counselors can enact community-based initiatives that position Filipino leaders 
to support the larger Filipino community (Guo et al., 2018; Maxwell et al., 2012; Nadal, 2021). For example, professional counselors can train Filipino leaders and community members to share information about coping responses (e.g., mindfulness, yoga, and diaphragmatic breathing) that mitigate the deleterious effects of racism, colonialism, and COVID-19-related stress. Professional counselors can also work with community members to establish Filipino-led wellness groups that frame discussions about stress within the broader context of health and wellness. Assessing for previous assumptions about mental health literacy may be helpful to normalize group discussions about stress and mental health. As outreach initiatives and community partnerships are established within the context of COVID-19, professional counselors must consider how they develop marketing materials for counseling services that appropriately reflect the cultural and linguistic diversity of Filipinos and invite input from Filipino community leaders (Campbell, 2019; Graham et al., 2018).

\section{Conclusion}

The cumulative effects of colonialism and racism continue to influence the mental health and visibility of Filipino communities within the global crisis of COVID-19. Unlike other AAPI subgroups, experiences of pandemic-related distress in Filipinos are additionally compounded by their distinct history of colonization, cultural values, and low levels of help-seeking behaviors. Specific interventions for culturally responsive counseling and outreach for Filipino communities are critical (Choi et al., 2017; David \& Nadal, 2013; David et al., 2017; Tuazon et al., 2019) and were outlined in this article. Professional counselors, especially those in community settings, have numerous opportunities to enact a systematic plan of action that integrates culture, health, and policy (Chan \& Henesy, 2018; Nadal, 2021). These interventions illuminate a longstanding and never more urgent call to action for extending efforts and initiatives to increase the visibility of Filipino communities and support individuals of Filipino descent in counseling.

\section{Conflict of Interest and Funding Disclosure}

The authors reported no conflict of interest or funding contributions for the development of this manuscript.

\section{References}

Abe-Kim, J., Gong, F., \& Takeuchi, D. (2004). Religiosity, spirituality, and help-seeking among Filipino Americans: Religious clergy or mental health professionals? Journal of Community Psychology, 32(6), 675689. https://doi.org/10.1002/jcop.20026

Abe-Kim, J., Takeuchi, D. T., \& Hwang, W.-C. (2002). Predictors of help seeking for emotional distress among Chinese Americans: Family matters. Journal of Consulting and Clinical Psychology, 70(5), 1186-1190. https://doi.org/10.1037/0022-006X.70.5.1186

Adia, A. C., Nazareno, J., Operario, D., \& Ponce, N. A. (2020). Health conditions, outcomes, and service access among Filipino, Vietnamese, Chinese, Japanese, and Korean adults in California, 2011-2017. American Journal of Public Health, 110(4), 520-526. https://doi.org/10.2105/AJPH.2019.305523

Adia, A. C., Ng, M. J., Quilantang, M. I., Restar, A. J., Hernandez, L. I., Imperial, R. H., Nazareno, J., \& Operario, D. (2019). Collective coping strategies for HIV-related challenges among men who have sex with men in Manila, Philippines. AIDS Education and Prevention, 31(5), 479-490. https://doi.org/10.1521/aeap.2019.31.5.479 
Afable, A., Ursua, R., Wyatt, L. C., Aguilar, D., Kwon, S. C., Islam, N. S., \& Trinh-Shevrin, C. (2016). Duration of US residence is associated with overweight risk in Filipino immigrants living in New York metro area. Family and Community Health, 39(1), 13-23. https://doi.org/10.1097/FCH.0000000000000086

Angan, J. (2013). Beyond the beach: The untold story of Boracay's Ati tribe. GMA News Online. https://www.gmanet work.com/news/lifestyle/artandculture/313920/beyond-the-beach-the-untold-story-of-boracay-s-ati-tribe/ story

Appel, H. B., Huang, B., Ai, A. L., \& Lin, C. J. (2011). Physical, behavioral, and mental health issues in Asian American women: Results from the National Latino Asian American Study. Journal of Women's Health, 20(11), 1703-1711. https://doi.org/10.1089/jwh.2010.2726

Araneta, E. G. (1993). Psychiatric care of Filipino Americans. In A. C. Gaw (Ed.), Culture, Ethnicity, and Mental Illness (pp. 377-411). American Psychiatric Association.

Asian Journal Press. (2018). New census data shows more than four million Filipinos in the US. https://www.asian journal.com/usa/dateline-usa/new-census-data-shows-more-than-four-million-filipinos-in-the-us

Augsberger, A., Yeung, A., Dougher, M., \& Hahn, H. C. (2015). Factors influencing the underutilization of mental health services among Asian American women with a history of depression and suicide. BMC Health Services Research, 15(1), 1-11. https://doi.org/10.1186/s12913-015-1191-7

Batalova, J. (2020). Immigrant health-care workers in the United States. Migration Policy Institute. https://www. migrationpolicy.org/article/immigrant-health-care-workers-united-states-2018

Bautista, V. (1999). The Filipino Americans: From 1763 to the present: Their history, culture, and traditions. Bookhaus.

Bhimla, A., Yap, L., Lee, M., Seals, B., Aczon, H., \& Ma, G. X. (2017). Addressing the health needs of high-risk Filipino Americans in the greater Philadelphia region. Journal of Community Health, 42(2), 269-277. https://doi.org/10.1007/s10900-016-0252-0

Budiman, A., Cilluffo, A., \& Ruiz, N. G. (2019). Key facts about Asian origin groups in the U.S. Pew Research Center. https://www.pewresearch.org/fact-tank/2019/05/22/key-facts-about-asian-origin-groups-in-the-u-s

Campbell, K. M. (2019). Race, gender, and health equity. Journal of Best Practices in Health Professions Diversity, 11(2), 155-157.

Centeno, R. P. R., \& Fernandez, K. T. G. (2020). Effect of mindfulness on empathy and self-compassion: An adapted MBCT program on Filipino college students. Behavioral Sciences, 10(3), 1-15.

https://doi.org/10.3390/bs10030061

Centers for Disease Control and Prevention. (2021). People with certain medical conditions. Retrieved March 14, 2021, from https://www.cdc.gov/coronavirus/2019-ncov/need-extra-precautions/people-withmedical-conditions.html?CDC AA refVal=https\%3A\%2F\%2Fwww.cdc.gov\%2Fcoronavirus \%2F2019ncov\%2Fneed-extra-precautions $\% 2$ Fgroups-at-higher-risk.html

Chan, C. D., \& Henesy, R. K. (2018). Navigating intersectional approaches, methods, and interdisciplinarity to health equity in LGBTQ+ communities. Journal of LGBT Issues in Counseling, 12(4), 230-247. https://doi.org/10.1080/15538605.2018.1526157

Chan, C. D., Henesy, R. K., \& Erby, A. N. (2019). Toward praxis, promise, and futures of intersectionality in multimethod counseling research. Counseling Outcome Research and Evaluation, 10(1), 12-18. https://doi.org/10.1080/21501378.2018.1562845

Choi, Y., Park, M., Lee, J. P., Kim, T. Y., \& Tan, K. (2017). Culture and family process: Examination of culturespecific family process via development of new parenting measures among Filipino and Korean American families with adolescents. In Y. Choi \& H. C. Hahm (Eds.), Asian American parenting: Family process and intervention (pp. 37-68). Springer. https://doi.org/10.1007/978-3-319-63136-3_3

Choi, Y., Park, M., Noh, S., Lee, J. P., \& Takeuchi, D. (2020). Asian American mental health: Longitudinal trend and explanatory factors among young Filipino- and Korean Americans. SSM - Population Health, 10, 1-10. https://doi.org/10.1016/j.ssmph.2020.100542

Choy, C. C. (2003). Empire of care: Nursing and migration in Filipino American history. Duke University Press.

David, E. J. R. (2020). Addressing anti-Black microaggressions in Filipino families. Psychology Today. https://www. psychologytoday.com/us/blog/unseen-and-unheard/202006/addressing-anti-black-microaggressions-infilipino-families-0

David, E. J. R., \& Nadal, K. L. (2013). The colonial context of Filipino American immigrants' psychological experiences. Cultural Diversity and Ethnic Minority Psychology, 19(3), 298-309.

https://doi.org/10.1037/a0032903 
David, E. J. R., \& Okazaki, S. (2006a). Colonial mentality: A review and recommendation for Filipino American psychology. Cultural Diversity and Ethnic Minority Psychology, 12(1), 1-16. https://doi.org/10.1037/1099-9809.12.1.1

David, E. J. R., \& Okazaki, S. (2006b). The Colonial Mentality Scale (CMS) for Filipino Americans: Scale construction and psychological implications. Journal of Counseling Psychology, 53(2), 241-252. https://doi.org/10.1037/0022-0167.53.2.241

David, E. J. R., Sharma, D. K. B., \& Petalio, J. (2017). Losing kapwa: Colonial legacies and the Filipino American family. Asian American Journal of Psychology, 8(1), 43-55. https://doi.org/10.1037/aap0000068

David, E. J. R., Schroeder, T. M., \& Fernandez, J. (2019). Internalized racism: A systematic review of the psychological literature on racism's most insidious consequence. Journal of Social Issues, 75(4), 1057-1086. https://doi.org/10.1111/josi.12350

Day-Vines, N. L., Booker Ammah, B., Steen, S., \& Arnold, K. M. (2018). Getting comfortable with discomfort: Preparing counselor trainees to broach racial, ethnic, and cultural factors with clients during counseling. International Journal for the Advancement of Counselling, 40(2), 89-104. https://doi.org/10.1007/s10447-017-9308-9

Day-Vines, N. L., Cluxton-Keller, F., Agorsor, C., Gubara, S., \& Otabil, N. A. A. (2020). The multidimensional model of broaching behavior. Journal of Counseling \& Development, 98(1), 107-118. https://doi.org/10.1002/jcad.12304

de Torres, S. (2002). Understanding persons of Philippine origin: A primer for rehabilitation service providers. Center for Institutional Rehabilitation Research Information and Exchange. http://cirrie-sphhp.webapps.buffalo.edu/ culture/monographs/philippines.php

Diemer, M. A., Rapa, L. J., Voight, A. M., \& McWhirter, E. H. (2016). Critical consciousness: A developmental approach to addressing marginalization and oppression. Child Development Perspectives, 10(4), $216-221$. https://doi.org/10.1111/cdep.12193

Edman, J. L., \& Johnson, R. C. (1999). Filipino American and Caucasian American beliefs about the causes and treatment of mental problems. Cultural Diversity and Ethnic Minority Psychology, 5(4), 380-386. https://doi.org/10.1037/1099-9809.5.4.380

Enriquez, V. G. (2010). From colonial to liberation psychology: The Philippine experience (2nd ed.). University of the Philippines Press.

Espiritu, Y. L. (2016). Gender, migration, and work: Filipina health care professionals to the United States. In M. Zhou \& A. C. Ocampo (Eds.), Contemporary Asian America: A multidisciplinary reader (3rd ed., pp. 236-256). New York University Press.

Flynn, P. M., Betancourt, H., Emerson, N. D., Nunez, E. I., \& Nance, C. M. (2020). Health professional cultural competence reduces the psychological and behavioral impact of negative healthcare encounters. Cultural Diversity and Ethnic Minority Psychology, 26(3), 271-279. https://doi.org/10.1037/cdp0000295

Ghimire, S., Cheong, P., Sagadraca, L., Chien, L.-C., \& Sy, F. S. (2018). A health needs assessment of the Filipino American community in the greater Las Vegas area. Health Equity, 2(1), 334-348. https://doi.org/10.1089/heq.2018.0042

Gong, F., Gage, S.-J. L., \& Tacata, L. A., Jr. (2003). Helpseeking behavior among Filipino Americans: A cultural analysis of face and language. Journal of Community Psychology, 31(5), 469-488. https://doi.org/10.1002/jcop.10063

Graham, L. F., Scott, L., Lopeyok, E., Douglas, H., Gubrium, A., \& Buchanan, D. (2018). Outreach strategies to recruit low-income African American men to participate in health promotion programs and research: Lessons from the Men of Color Health Awareness (MOCHA) project. American Journal of Men's Health, 12(5), 1307-1316. https://doi.org/10.1177/1557988318768602

Griffith, D. M. (2018). “Centering the margins”: Moving equity to the center of men's health research. American Journal of Men's Health, 12(5), 1317-1327. https://doi.org/10.1177/1557988318773973

Guo, M., Quensell, M., Chang, A., Miyamura, J., \& Sentell, T. (2018). Understanding of key obstetric quality terminology by Asian and Pacific Islander subgroups: Implications for patient engagement and health equity. Maternal and Child Health Journal, 22(11), 1543-1549. https://doi.org/10.1007/s10995-018-2597-8

Javier, J. R., Supan, J., Lansang, A., Beyer, W., Kubicek, K., \& Palinkas, L. A. (2014). Preventing Filipino mental health disparities: Perspectives from adolescents, caregivers, providers, and advocates. Asian American Journal of Psychology, 5(4), 316-324. https://doi.org/10.1037/a0036479 
Jeung, R., \& Nham, K. (2020). Incidents of Coronavirus-related discrimination. Asian Pacific Policy \& Planning Council. http://www.asianpacificpolicyandplanningcouncil.org/wp-content/uploads/STOP AAPI HATE MONTHLY REPORT 4 23 20.pdf

Jones-Smith, E. (2019). Culturally diverse counseling: Theory and practice. SAGE.

Juang, L. P., Yoo, H. C., \& Atkin, A. (2017). A critical race perspective on an empirical review of Asian American parental racial-ethnic socialization. In Y. Choi \& H. C. Hahm (Eds.), Asian American parenting: Family process and intervention (pp. 11-35). Springer. https://doi.org/10.1007/978-3-319-63136-3_2

Kim, G., Chiriboga, D. A., Bryant, A., Huang, C.-H., Crowther, M., \& Ma, G. X. (2012). Self-rated mental health among Asian American adults: Association with psychiatric disorders. Asian American Journal of Psychology, 3(1), 44-52. https://doi.org/10.1037/a0024318BB

Klest, B., Freyd, J. J., Hampson, S. E., \& Dubanoski, J. P. (2013). Trauma, socioeconomic resources, and self-rated health in an ethnically diverse adult cohort. Ethnicity $\mathcal{E}$ Health, 18(1), 97-113. https://doi.org/10.1080/13557858.2012.700916

Li, M. (2014). Discrimination and psychiatric disorder among Asian American immigrants: A national analysis by subgroups. Journal of Immigrant and Minority Health, 16, 1157-1166.

https://doi.org/10.1007/s10903-013-9920-7

Litam, S. D. A. (2020). “Take your Kung-Flu back to Wuhan”: Counseling Asians, Asian Americans, and Pacific Islanders with race-based trauma related to COVID-19. The Professional Counselor, 10(2), 144-156. https://doi.org/10.15241/sdal.10.2.144

Litam, S. D. A., \& Hipolito-Delgado, C. P. (2021). When being "essential" illuminates disparities: Counseling clients affected by COVID-19. Journal of Counseling \& Development, 99(1), 3-10. https://doi.org/10.1002/jcad.12349

Litam, S. D. A., \& Oh, S. (2020). Ethnic identity and coping strategies as moderators of COVID-19 racial discrimination experiences among Chinese Americans. Counseling Outcome Research and Evaluation. Online publication. https://doi.org/10.1080/21501378.2020.1814138

Martinez, A. B., Co, M., Lau, J., \& Brown, J. S. L. (2020). Filipino help-seeking for mental health problems and associated barriers and facilitators: A systematic review. Social Psychiatry and Psychiatric Epidemiology, 55, 1397-1413. https://doi.org/10.1007/s00127-020-01937-2

Maxwell, A. E., Danao, L. L., Cayetano, R. T., Crespi, C. M., \& Bastani, R. (2012). Evaluating the training of Filipino American community health advisors to disseminate colorectal cancer screening. Journal of Community Health, 37(6), 1218-1225. https://doi.org/10.1007/s10900-012-9557-9

McFarling, U. L. (2020). Nursing ranks are filled with Filipino Americans. The pandemic is taking an outsized toll on them. Stat. https://www.statnews.com/2020/04/28/coronavirus-taking-outsized-toll-on-filipino-american-nurses

Mendoza, R. L. (2014). The skin whitening industry in the Philippines. Journal of Public Health Policy, 35(2), 219238. https://doi.org/10.1057/jphp.2013.50

Nadal, K. L. (2000). F/Pilipino American substance abuse: Sociocultural factors and methods of treatment. Journal of Alcohol and Drug Education, 46(2), 26-36.

Nadal, K. L. (2021). Filipino American psychology: A handbook of theory, research, and clinical practice (2nd ed.). Wiley. https://doi.org/10.1002/9781119677109

Nadal, K. L., Griffin, K. E., Wong, Y., Hamit, S., \& Rasmus, M. (2014). The impact of racial microaggressions on mental health: Counseling implications for clients of color. Journal of Counseling \& Development, 92(1), 57-66. https://doi.org/10.1002/j.1556-6676.2014.00130.x

National Nurses United. (2020). Sins of omission: How government failures to track COVID-19 data have led to more than 1,700 health care worker deaths and jeopardize public health. https://www.nationalnursesunited.org/sites/ default/files/nnu/graphics/documents/0920_Covid19 SinsOfOmission_Data_Report.pdf

Ocampo, A. C. (2016). The Latinos of Asia: How Filipino Americans break the rules of race. Stanford University Press.

Oh, S., Litam, S. D. A., \& Chang, C. (in press). COVID-19 fueled subtle and blatant racism and stress-related growth among international Asians in the United States: The roles of ethnic identity, resiliency, and coping. Asian American Journal of Psychology.

Pacquiao, D. (2004). Overcoming stigma and mental illness among Filipinos. Presentation at the National Conference of the New York Coalition for Asian Mental Health. New York Academic of Medicine, New York. 
Pasco, A. C. Y., Morse, J. M., \& Olson, J. K. (2004). Cross-cultural relationships between nurses and Filipino Canadian patients. Journal of Nursing Scholarship, 36(3), 239-246. https://doi.org/10.1111/j.1547-5069.2004.04044.x

Pew Research Center. (2013). The rise of Asian Americans. https://www.pewsocialtrends.org/2012/06/19/the-rise-ofasian-americans

Poon, L. (2020, April 7). What bigotry looks like during social distancing. Citylab. https://www.citylab.com/equity/ 2020/04/coronavirus-racism-hate-crimes-asian-americans-xenophobia/609517

Ratts, M. J., \& Greenleaf, A. T. (2018). Counselor-advocate-scholar model: Changing the dominant discourse in counseling. Journal of Multicultural Counseling and Development, 46(2), 78-96. https://doi.org/10.1002/jmcd.12094

Ratts, M. J., Singh, A. A., Nassar-McMillan, S., Butler, S. K., \& McCullough, J. R. (2016). Multicultural and social justice counseling competencies: Guidelines for the counseling profession. Journal of Multicultural Counseling and Development, 44(1), 28-48. https://doi.org/10.1002/jmcd.12035

Ruiz, N. G., Horowitz, J. M., \& Tamir, C. (2020). Many Black and Asian Americans say they have experienced discrimination amid the COVID-19 outbreak. Pew Research Center. https://www.pewsocialtrends. org/2020/07/01/many-black-and-asian-americans-say-they-have-experienced-discrimination-amid-thecovid-19-outbreak

Sanchez, F., \& Gaw, A. (2007). Mental health care of Filipino Americans. Psychiatric Services, 58(6), 810-815. https://doi.org/10.1176/ps.2007.58.6.810

Seider, S., Clark, S., \& Graves, D. (2020). The development of critical consciousness and its relation to academic achievement in adolescents of color. Child Development, 91(2), e451-e474. https://doi.org/10.1111/cdev.13262

Shea, M., \& Yeh, C. (2008). Asian American students' cultural values, stigma, and relational self-construal: Correlates of attitudes toward professional help-seeking. Journal of Mental Health Counseling, 30(2), 157-172. https://doi.org/10.17744/mehc.30.2.g662g5l2r1352198

Smith, M. J., \& Weinstock, D. (2019). Reducing health inequities through intersectoral action: Balancing equity in health with equity for other social goods. International Journal of Health Policy and Management, 8(1), 1-3. https://doi.org/10.15171/IJHPM.2018.103

Sue, D. W., Sue, D., Neville, H. A., \& Smith, L. (2019). Counseling the culturally diverse: Theory and practice (8th ed.). Wiley.

Taylor, S., Landry, C. A., Paluszek, M. M., Fergus, T. A., McKay, D., \& Asmundson, G. J. G. (2020). Development and initial validation of the COVID Stress Scales. Journal of Anxiety Disorders, 72(2020), 1-7. https://doi.org/10.1016/j.janxdis.2020.102232

Tuason, M. T. G., Taylor, A. R., Rollings, L., Harris, T., \& Martin, C. (2007). On both sides of the hyphen: Exploring the Filipino-American identity. Journal of Counseling Psychology, 54(4), 362-372. https://doi.org/10.1037/0022-0167.54.4.362

Tuazon, V. E., Gonzalez, E., Gutierrez, D., \& Nelson, L. (2019). Colonial mentality and mental health help-seeking of Filipino Americans. Journal of Counseling \& Development, 97(4), 352-363. https://doi.org/10.1002/jcad.12284

U.S. Department of Justice. (2020). Coronavirus is no excuse for hate: Remembering Vincent Chin. Department of Justice, U.S. Attorneys' Office, District of Idaho. https://www.justice.gov/usao-id/pr/coronavirus-no-excuse-hate

Watts, R. J., \& Hipolito-Delgado, C. P. (2015). Thinking ourselves to liberation? Advancing sociopolitical action in critical consciousness. The Urban Review, 47(5), 847-867. https://doi.org/10.1007/s11256-015-0341-x

Woo, B., Maglalang, D. D., Ko, S., Park, M., Choi, Y., \& Takeuchi, D. T. (2020). Racial discrimination, ethnic-racial socialization, and cultural identities among Asian American youths. Cultural Diversity E Ethnic Minority Psychology, 26(4), 447-459. https://doi.org/10.1037/cdp0000327

Worldometer. (n.d.). Covid-19 coronavirus pandemic. https://www.worldometers.info/coronavirus/\#countries 